
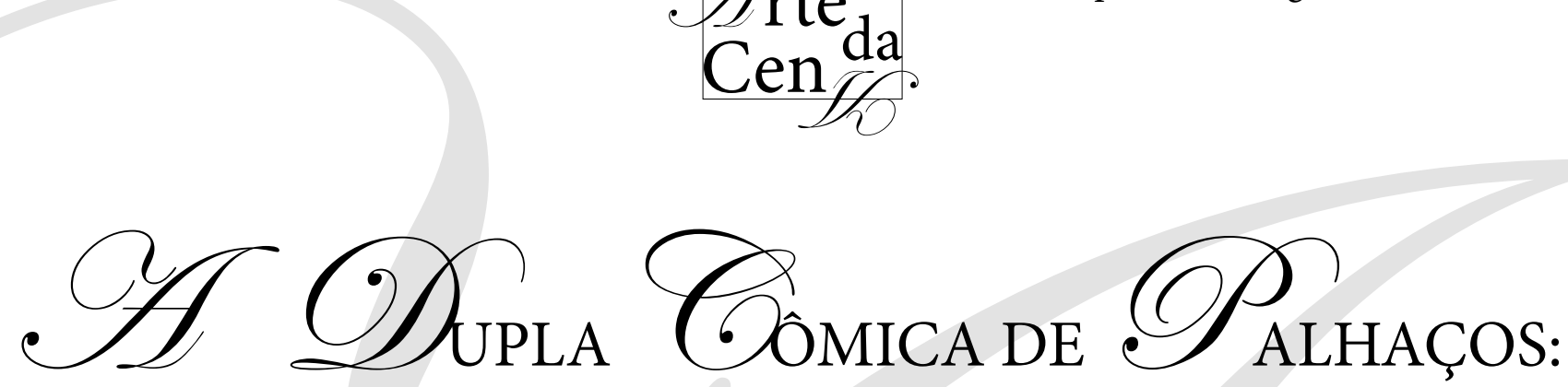

\title{
PARCERIA DE JOGO, OPERAÇÃO DE FUNÇÕES E PRINCÍPIOS DA ARTE CLOWNESCA
}

\author{
"The comic pair of clowns: \\ game partnership, operation of functions and principles of the clown art"
}

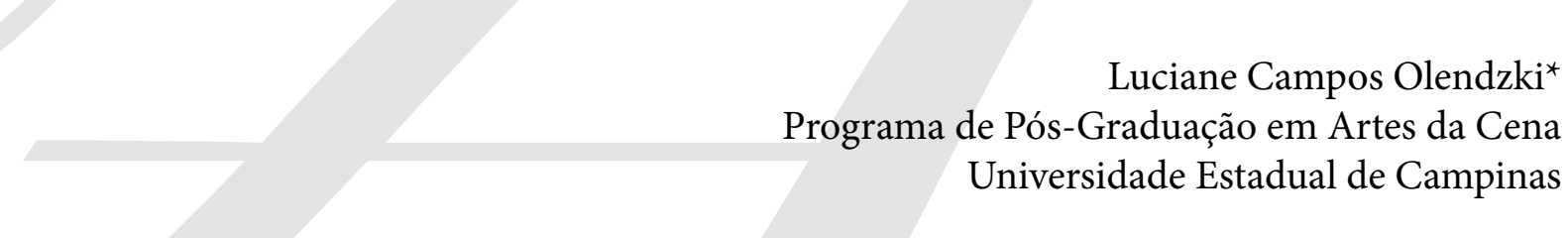

RESUMO: Primeiramente, apresentamos informações históricas sobre a dupla clássica de palhaços surgida no circo moderno europeu (Clown Branco e Augusto), abordando traços e qualidades que configuram esta dupla. Com isso, buscamos evidenciar determinadas funções e operações da dupla clássica para o desenvolvimento da contracenação, do jogo cômico e da cena clownesca, para além da fixação em modelos ou tipos dados. Logo, abordamos alguns exemplares de diversas (re)configurações e formas de duplas cômicas presentes na cena da palhaçaria contemporânea, realizando articulações com princípios operacionais da dupla Branco e Augusto. Por fim, buscamos associações entre princípios operacionais da dupla clássica e da própria poética clownesca.

Palavras-chave: Clown Branco e Augusto; dupla de palhaços; poética clownesca.

\begin{abstract}
Initially, we present historic information on the classic clown pair that arouse in the modern European circus (White Clown and Auguste), addressing traits and qualities that characterize this pair. Thus, we intend to evidence certain functions and operations of the classic pair for the development of the performance, the comic game and the clowning scene, beyond the fixation in given models or types. Therefore, we discuss some examples of diverse (re)configurations and forms of comic pairs present in the scene of contemporary clownery, performing acts with operational principles of the pair White and Auguste. Finally, we search associations between operational principles of the classic pair and the clown poetics itself.
\end{abstract}

Keywords: White Clown and Auguste; pair of clowns; clown poetry.

Luciane Campos Olendzki - A dupla cômica de palhaços: parceria de jogo, operação de funções e princípios da arte clownesca. Revista Arte da Cena, Goiânia, v. 2, n. 3, p. 33-52, Jul.-Dez./2016. 
CLOWN BRANCO E AUGUSTO: "FAÇA-ME RIR, PALHAÇO!”

A dupla composta pelos tipos cômicos "Clown Branco e Augusto" surgiu no circo moderno europeu, definindo-se a partir da dupla de palhaços Foottit e Chocolat que atuava no circo parisiense Hippodrome Du Champ de Mars, a partir de 1894.

O Clown Branco (Foottit) atuava como um tipo autoritário e despótico no jogo e na relação com o Augusto (Chocolat), dando-lhe bofetadas e chutes ao bel-prazer, fazendo-o de serviçal, repreendendo-o, corrigindo-o e tratando-o com malvadeza, esperteza e malícia; sempre tentando redimi-lo e ludibriá-lo por artimanhas e superioridade intelectual. Já o Augusto apresentava-se como figura estúpida, crédula e inapta, sempre atrapalhado, sem conseguir realizar as coisas de forma eficiente e correta.

$\mathrm{Na}$ orquestração desse jogo baseado em conflitos, hierarquias, disputas, especialmente no autoritarismo e na superioridade do Branco em relação à inaptidão, inferioridade e servilismo do Augusto, para o sucesso da produção e do efeito cômico, há de se considerar a presença de um traço arraigado da sociedade da época: o racismo colonial europeu e a relação do senhor (branco) e do escravo (negro).
Chocolat (Rafael Padilla, 1868-1917) foi um dos primeiros artistas negros do circo europeu, nascido na condição de escravo em Havana (Cuba), vendido ainda criança para um rico comerciante espanhol em Bilbao, tornando-se escravo na casa da família colonial, de onde fugiu quando jovem. Para sobreviver e ganhar uns trocados, além de prestar vários serviços, fazia exibições de dança e alongamento nos halls dos cafés, onde foi visto, quando tinha 16 anos, pelo palhaço Tony Grice. Grice encantou-se com Rafael e o convidou para tornar-se seu aprendiz de palhaço e vir a atuar como seu partner, em troca de moradia, alimentação e um pequeno salário. Além de atuar como partner, Rafael também era serviçal na vida privada e na casa de família de Grice. A dupla de palhaços Grice e Chocolat acabou por atuar no Cirque Nouveau, onde George Foottit também era palhaço.

George Foottit (1864-1921) nasceu em Manchester (Inglaterra), descendia de família circense, onde recebeu formação em arte equestre, acrobacias, música e palhaçaria. Seu pai era palhaço e teve seu próprio circo itinerante, onde Foottit estreou como réplica miniatura do palhaço do pai, aos três anos de idade. Em 1886, Foottit se tornou famoso por sua entrada clownesca que era uma paródia de uma equilibrista em evoluções virtuosas sobre o dorso de um cavalo, em que mesclava a graça e a singeleza de uma bailarina

Luciane Campos Olendzki - A dupla cômica de palhaços: parceria de jogo, operação de funções e princípios da arte clownesca. Revista Arte da Cena, Goiânia, v. 2, n. 3, p. 33-52, Jul.-Dez./2016. 
com tutu, em contraste com sua figura travestida, rude, desajeitada e masculina.

Foottit interessou-se pela figura e potencial cômicos de Chocolat, especialmente diante de acontecimentos fora de cena, em que ele presenciou as reações de Rafael quando era repreendido e maltratado por Grice, vendo graça nas situações de desgraça do colega palhaço. Footit acabou por convencer o diretor do circo em tornar Chocolat um palhaço independente de Grice, assim, ele se tornou partner também de outros palhaços no Cirque Noveau.

Chocolat tornou-se parceiro regular de $\mathrm{Ge}$ orge Foottit em 1890, estreando em uma entrada que se tornou uma grande atração e causou polêmica na época. A entrada era uma paródia clownesca de uma cena de um espetáculo em cartaz em Paris, com estrondoso sucesso de público e crítica, em que Footit, de forma satírica e jocosa, imitava a morte dramática e grandiloquente de Cleópatra, então interpretada por Sarah Bernhardt - atriz e grande diva do teatro na época. Foottit jogava o papel de Cleópatra-Sarah e Chocolat o de Marco Antônio. A própria diva imaculada, estrela de um espetáculo digno de seriedade e consagrado pela crítica, foi ao circo para verificar as audácias impetuosas dos tais palhaços parodiadores. A diva entrou na plateia minutos antes de começar a entrada clownesca, rodeada por uma comitiva que fez parar o show ao chamar a atenção de todos. Assim que Footit entrou em cena, Sarah levantou-se da cadeira e se dirigiu a ele, com a seguinte sentença: "Faça-me rir, palhaço"! Foottit não se acanhou e despretensiosamente seguiu com sua sátira jocosa, o que acabou conquistando o riso e a aceitação da diva.

Chocolat e Footit vieram a tornar-se uma dupla de grande sucesso do Cirque Nouveau de Paris, em que os tipos cômicos "Clown Branco e Augusto" foram cada vez mais sendo definidos, pautados em um jogo agressivo e violento dentro de uma atmosfera lúdica e hilária, cheia de trapaças, conflitos, crueldade, atrapalhação e dificuldade em fazer as coisas. O desacerto entre a dupla era evidenciado, mas, especialmente, sobrepunha-se um forte elo de complementaridades díspares. Foottit configurava- se como um tipo mandão e violento com Chocolat, que era um tipo serviente, idiota, estúpido, crédulo e cheio de graça.

As entradas clownescas de Footit e Chocolat, ainda que envolvessem a caricaturização cômica da opressão, da pretensa supremacia e superioridade do branco, não-escravo, com status social salvaguardado de cidadão de direitos e bens, contraditoriamente também apoiava-se nos valores de uma sociedade colonial escravocrata, em que bater em um negro, subjugá-lo, expô-lo como ser inferior e ridículo, ter de ensiná-lo a

Luciane Campos Olendzki - A dupla cômica de palhaços: parceria de jogo, operação de funções e princípios da arte clownesca. Revista Arte da Cena, Goiânia, v. 2, n. 3, p. 33-52, Jul.-Dez./2016. 
fazer as coisas, de forma deliberada e ainda como brincadeira permitida, era algo potencialmente engraçado. O nome "Chocolat", do palhaço Augusto da dupla, era um insulto racial dirigido aos negros, o que parecia inocente e divertido ao público dos tempos coloniais.

Chocolat apresentava-se com uma indumentária chique e elegante da moda francesa da época. A figura de um negro buscando vestir-se como senhor de bens, com trajes aristocráticos, refinados de alta classe, em contraste e incoerência com seu comportamento tolo, inapto e tido como inculto, era motivo de graça. Em relação aos figurinos da dupla, não havia unidade de composição estética de forma, estilo ou época: Chocolat apresentava-se com um traje existente no cotidiano e na sociedade de seu tempo; Foottit vestia uma indumentária não-realista (incluindo a maquiagem), aportando um universo atrelado à fantasia e à ficção, com possíveis reminiscências aos figurinos dos cômicos medievais de feira e da Commedia dell'Arte (especialmente do tipo Pagliaccio ou Pedrolino).

Em geral, as entradas clownescas do circo moderno europeu tinham como referência principal as cenas e jogos realizados pelos artistas (jograis) de feira e cômicos medievais, assim como, os lazzis ${ }^{1}$ da Commedia dell'Arte, que eram aproveitados, adaptados e desenvolvidos pelos palhaços do circo. As duplas de zannis (servos) da Commedia já contêm o jogo cômico e contra pontual em que geralmente há um esperto e ardiloso (Briguella ou Pulcinella) e o outro crédulo, idiota e tonto (Arlequim). As entradas de Foottit e Chocolat envolviam improvisação, entretanto eram bem definidas e estruturadas, apresentando um enredo específico, pautadas em comicidade física (com evidência e desenvolvimento de ações físicas e expressividade corporal), com uso de diálogo. Pelo enorme sucesso da dupla, suas entradas passaram a ser imitadas por várias outras duplas de palhaços, que as reinterpretavam de acordo com suas potencialidades e especificidades cômicas.

O Clown Branco teve seu apogeu com Antonet (1872-1935), que realizava um jogo agressivo, abusivo e autoritário em relação ao Augusto. Antonet era Umberto Guillaume, um italiano, que primeiramente foi palhaço Augusto em uma dupla com o irmão, e depois passou a atuar, sozinho e com outros partners, como "Auguste de Soirée"2 em circos. Antonet desenvolveu e definiu seu papel de "Clown Branco" ao associar-se ao palhaço Little Walter, que jogava o Augusto, com quem formou uma dupla de sucesso por vários anos. Antonet dirigia as entradas com "mão de ferro" e apresentava um comportamento controlador, desrespeitoso e autoritário, dentro e fora da pista, o que fora a causa do término da dupla, e também de muitos outros duos de trabalho que ele tentou

Luciane Campos Olendzki - A dupla cômica de palhaços: parceria de jogo, operação de funções e princípios da arte clownesca. Revista Arte da Cena, Goiânia, v. 2, n. 3, p. 33-52, Jul.-Dez./2016. 
formar.

Os parceiros de Antonet obtinham enorme simpatia e consagração com o público, como palhaço suíço Grock (1880-1959) que também se separou dele e seguiu sua carreira de palhaço, vindo a realizar espetáculos solos e com outros partners, tornando-se um dos palhaços mais brilhantes e admirados do mundo. Depois de Antonet a figura tradicional do Clown Branco do circo moderno europeu entra em declínio.

Tradicionalmente, o Clown Branco apresentava-se com a maquiagem da cara toda branca, com alguns traços sinteticamente marcantes de cor única (geralmente preto), na boca, no nariz e sendo a sobrancelha basicamente a "assinatura" entre um e outro clown Branco. Tal maquiagem é associada à de Pedrolino da Commedia dell'Arte, da cara branca enfarinhada, que também foi uma referência usada por Joseph Grimaldi (17781837), tido como percursor ou "pai dos clowns", na criação de sua maquiagem própria. $\mathrm{O}$ uso do chapéu cônico como parte da indumentária também é um elemento recorrente de caracterização dos Clowns Brancos. A partir de Antonet, os figurinos dos Clowns Brancos se tornaram cada vez mais excessivos, estilizados, elegantes e pomposos, com bordados cheios de brilhos e lantejoulas.

O palhaço Augusto não apresentava uma maquiagem característica, havendo muitas variações. O figurino geralmente era relacionado a uma roupa da época, considerada elegante e formal, porém já bastante surrada, com possíveis desajustes e descompassos de tamanho (partes grandes ou pequenas demais), quase sempre um fraque em preto e branco. Como se o Augusto vestisse uma roupa de segunda mão, que não lhe cai bem e é desproporcional. Por exemplo, Charles Chaplin com seu terno, bengala e chapéu coco, um traje de um cidadão comum de seu tempo, com ares de formalidade e algum status social. O desacerto e a incoerência do palhaço Augusto entre ser e parecer, a sua pretensão em querer parecer ou se passar, por exemplo, por um cidadão de bem ou aristocrata é explicitamente incongruente com seu comportamento e tipo idiota, desajustado, tolo e fora dos padrões. Deste modo, exposto comicamente com todos os seus defeitos e presunções, acaba por produzir o riso e a empatia do público. Visto que, o palhaço ainda que pretenda enganar e passar-se pelo o que não é, torna tal intento evidente ao público, em um jogo cômico de incongruências e desajustes entre ser e parecer.

Ainda que o Augusto tente vestir-se como um cidadão comum, ele sempre se destaca e é percebido como um fora-de-lugar, pois não passa de um inadaptado, descompassado e inadequado aos padrões e protótipos sociais. Apesar de buscar vestir um traje comum ou mesmo aristocrático

Luciane Campos Olendzki - A dupla cômica de palhaços: parceria de jogo, operação de funções e princípios da arte clownesca. Revista Arte da Cena, Goiânia, v. 2, n. 3, p. 33-52, Jul.-Dez./2016. 


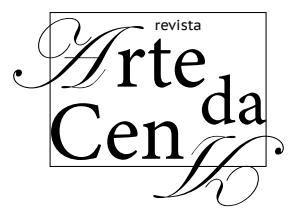

de seu tempo e inserir-se no mundo tal qual é, o Augusto apresenta atitudes e comportamentos desenquadrados e incoerentes com o mundo dado e os padrões estabelecidos. Desse modo, o Augusto cria um mundo próprio, apresentando modos não-convencionais de comportamento, ação e concepção que se chocam comicamente com o mundo dado. É justamente na inadaptação aos padrões estabelecidos e na criação lúdica e fantasiosa de outros modos de agir e ver o mundo, que reside um dos grandes vieses da potencialidade crítica, poética, satírica e paródica do palhaço Augusto, através do humor e da poesia cômica.

\section{PARCEIROS DE JOGO: CONTRASTE, CONFLITO E COMPLEMENTARIDADE}

Na relação da dupla de palhaços transparecem várias facetas positivas e negativas das relações humanas, compondo pequenos microcosmos e complementaridades que constroem o ser e o sentido de cada um, em uma unidade de relação e jogo à dois, que acaba por se tornar múltipla e universal. Para Fellini (1986, p. 106), as duas figuras (o Branco e o Augusto) "encarnam um mito que está dentro de cada um de nós - a reconciliação dos opostos, a unidade do ser”.

Na dupla do Clown Branco e Augusto revela-se um jogo de contrastes e complementaridades, em que os conflitos e diferenças tornam-se motes para a produção de comicidade e brincadeira. O conflito, a tensão, o contraste e a disparidade constituem o próprio elo, a conjugação e a interdependência da dupla, tanto para o desenvolvimento do jogo cômico, quanto para o desdobramento progressivo das ações e acontecimentos que constituem uma cena ou espetáculo clownesco. A oposição e o contraste entre os palhaços acabam formando a unidade da dupla e, ao mesmo o tempo, a caracterização e a definição de cada um. Nesse sentido, o Clown Branco o é em relação ao Augusto, e vice-versa. Tais características além de configurarem cada palhaço em um jogo de contrapontos, guia a forma de realizar as ações e a definição da lógica de cada um (sua maneira de jogar, agir e pensar,) aportando antagonismos de relações, objetivos e modos de fazer que aportam conflitos, problemas, desastres, desvios e desacertos essenciais ao desenvolvimento da dramaturgia das ações da cena clownesca.

$\mathrm{Na}$ relação contrapontual de contrários entre os parceiros inseparáveis de jogo, que muitas vezes possuem um objetivo comum, porém, modos distintos de realizá-lo, o Clown Branco se caracteriza como um ser pretensamente superior, mais encaixado aos padrões, valores sociais e acertos, um tipo bem-sucedido, de maior inteligência e razoabilidade em relação ao Augusto. Já o Augusto apresenta-se como um "marginal" - sempre à margem, uma figura torpe, de inteli-

Luciane Campos Olendzki - A dupla cômica de palhaços: parceria de jogo, operação de funções e princípios da arte clownesca. Revista Arte da Cena, Goiânia, v. 2, n. 3, p. 33-52, Jul.-Dez./2016. 
gência limitada, que não sabe ou não entende as coisas, evidenciando uma interpretação e visão particulares de mundo. O Augusto é associado à criança e ao animal pela manifestação desenfreada de instintos, impulsos e ações genuínas, com potente estado lúdico. Também, atrelado às manifestações do corpo e às necessidades básicas: comer, dormir, fazer sexo e, também, se divertir. Muitas vezes, o Augusto é associado à outras figuras, tais como: o bêbado, o vagabundo, o servo ou empregado de baixa hierarquia, o maltrapilho, o desempregado, o faminto e o sem-posses. O surgimento do palhaço Augusto na Europa, ocorre durante o período da Revolução Industrial, em que houve uma grande migração de campesinos para as cidades, que acabavam explorados e mal renumerados em fábricas, ou desempregados pelas ruas em situação de fome e marginalidade. Em sua caracterização, a figura do Augusto apresenta um corte social de classe, a exclusão dos padrões e sistemas sociais, também, o confronto com a ordem, o poder e o sistema instituídos. Contraditoriamente, apresenta-se como portador da alegria, liberdade e potencial daquele que estando à margem, se vira e encontra outras saídas, modos de existência e visão de mundo. Segundo Bolognesi (2003, p. 77 -78), a partir de 1880, “o Augusto se impôs como estilização da miséria, em meio a um ambiente social que prometia sua erradicação (...). O Branco seria a voz da ordem e o Augusto, o marginal, aquele que não se encaixa no progresso, na máquina e no macacão do operário industrial".

A dupla clássica acaba por conter traços de caricaturização de relações e tipos sociais, que muitas vezes acabam sendo subvertidas, por exemplo, quando o Augusto dá a volta por cima e acaba se saindo bem, como vencedor do jogo com o clown Branco. Em várias situações, o Branco acaba exposto pelo ridículo de sua vaidade, prepotência, petulância e pretensa superioridade. A hierarquia superior e a autoridade do Branco podem ser abaladas e transgredidas pelas peripécias, saídas surpreendentes e traquinagens do Augusto.

Em algumas entradas o Augusto, após ter sido prejudicado, violentado ou enganado, aprende o mecanismo da agressão ou do ludibrio usados pelo Branco, e os reproduz novamente, fazendo com que o Branco caia em sua própria armadilha ou ardil. Assim, o Augusto pode realizar uma contraditória revanche ou, por outra via, se safar por suas qualidades particulares de traquejo, malandragem, travessura, inocência, entendimento limitado, perspicácia e fantasia. Muitas vezes, nos procedimentos de dramaturgia, construção da cena e do jogo clownesco, o Augusto tem como aliados a distração, a falta de consciência sobre o que ocorre e o próprio acaso como forma de obter sucesso, vencer o jogo ou se dar bem, especialmente, quando o fracasso, a inaptidão, o perigo e

Luciane Campos Olendzki - A dupla cômica de palhaços: parceria de jogo, operação de funções e princípios da arte clownesca. Revista Arte da Cena, Goiânia, v. 2, n. 3, p. 33-52, Jul.-Dez./2016. 
a catástrofe lhe são iminentes.

Muitas vezes, o Branco conquista sua condição cômica, justamente, no momento que é abatido por uma situação ridícula, subjugado pelo riso, no instante em que é exposto em suas limitações e soberbas, já tão visíveis (e mesmo empáticas) ao público. O palhaço Branco acaba por cativar a plateia no disparate de sua pretensa soberba e inteligência, mas também revela sua vulnerabilidade quando erra, fracassa e se dá mal, ainda que momentaneamente. O papel do Branco acaba sendo relacionado a todas as figuras de poder, opressão, repressão, mando, ordem, cobrança e superioridade vigentes na sociedade. Portanto, o público, que em sua grande maioria vive aspectos da condição do Augusto em seu cotidiano, se regozija em ver a caricatura, a estupidez e o fracasso do Branco, assim como, as peripécias, liberdades e transgressões do Augusto em relação àquele.

O Branco precisa a todo momento do Augusto, afinal é nele que manda e é para ele que tudo demanda. Quando o Branco é acolhido pelo Augusto em um momento de fracasso e fragilidade, a dupla pode revelar uma tocante perspectiva sobre os afetos, vulnerabilidades, ilusões e vaidades das relações humanas, que, então, parecem ser acolhidas, redimidas pelo riso e a amizade, em uma relação que se pauta na parceria e na simplicidade de brincar juntos.
O jogo da dupla dos palhaços "Branco e Augusto" (como é comumente referida no jargão dos palhaços brasileiros) exige escuta e contracenação afinadíssimas, assim como, a consciência das funções e tipos específicos de cada um, para a consecução dos efeitos cômicos, o desenvolvimento da dramaturgia e do enredo das entradas.

A dupla de palhaços Branco e Augusto pode ser associada à vários possíveis contrastes que se expressam, se confrontam e operam mutuamente. $\mathrm{O}$ inteligente e o imbecil; o astuto e o ingênuo; o cidadão de bem e o vagabundo; o patrão e o empregado; o homem-da-lei e o fora-da-lei; o que ordena e o que obedece; o que ensina e o que aprende; o que bate e o que apanha; o que tem e o que não tem. A ordem e a desordem; o padrão e a exceção; o superior e o inferior; a vaidade e a despretensão; $\mathrm{o}$ ardil e a inocência; a posse e a miséria; a razão e a desrazão; a lógica e o absurdo; a realidade e a fantasia; o intelecto e o instinto. Como ainda coloca Fellini (1986, p. 107), o macho e a fêmea, o animal e o homem, o velho e a criança, o yin e o yang.

Para Fellini (idem, p. 106), o clown Branco está ao lado das formas moralistas, da repressão, do dever, das situações ideais, únicas, das divindades indiscutíveis. E o Augusto "é a criança que faz sujeira, se revolta ante tanta pretensa perfeição, se

Luciane Campos Olendzki - A dupla cômica de palhaços: parceria de jogo, operação de funções e princípios da arte clownesca. Revista Arte da Cena, Goiânia, v. 2, n. 3, p. 33-52, Jul.-Dez./2016. 
embebeda, rola no chão e na alma, numa rebeldia perpétua”. Ao fim, ambos são enganadores e enganados, vencedores e vencidos, em um espelho torpe e poético que reflete as limitações, fragilidades e potencialidades do ser humano sobre a ótica do riso e da brincadeira.

\section{CONFIGURAÇÕES NO CIRCO BRASILEIRO - PA- LHAÇO, AUGUSTO, MESTRE DE PISTA, ESCADA OU CROM}

Na tradição da palhaçaria brasileira, especialmente no circo, não se emprega o termo "clown" para nomear algum tipo específico, sendo usado a nomenclatura de palhaço que diz respeito especialmente ao tipo Augusto, também chamado de Toni ou Excêntrico. Bolognesi (2003, p. 91 et 97) em seu estudo sobre os palhaços, não encontrou nenhum Clown Branco na tradição do circo brasileiro, conforme os modelos do circo moderno europeu. Geralmente a figura do apresentador do circo ou Mestre de Pista realiza uma função similar ao do Clown Branco, como figura de autoridade, no jogo com o palhaço Augusto. Nesse caso, o Mestre de Pista atua diretamente com os palhaços, realizando o papel de partner na função de contraponto e de contraste para o desenvolvimento do jogo cômico do palhaço Augusto. o papel de condução e comando do espetáculo circense, ele apresenta as atrações circenses, suas falas pontuam, chamam a atenção, evidenciam o clímax, criam tempo dramático e suspense, dão ritmo às atrações apresentadas. Algumas vezes, o próprio dono ou diretor do circo é quem desempenha essa função. O Mestre de Pista é considerado a maior autoridade no picadeiro. Tradicionalmente, apresenta-se com um traje nobre - um desdobramento das figuras militares e aristocráticas da cavalaria dos primórdios do circo equestre ou de cavalinhos. Originalmente, o Mestre de Pista era o domador e diretor dos números equestres (BOLOGNESI, 2003, p. 68)

O Mestre de Pista que atua como partner do palhaço pode questioná-lo e repreendê-lo, dar ordens, exemplificar, ensinar ou apontar como fazer as coisas corretamente, dar deixas, apoios e motivos para o desdobramento da cena e jogo cômicos do palhaço. O Mestre de Pista efetua a função do Escada ou crom - um parceiro de jogo (geralmente um palhaço secundário) que atua com o palhaço principal, apoiando-o na preparação e efetuação de gags, piadas, desenvolvimento do enredo e desenlaces cômicos da cena. Fo (Cf. 2004, p. 208 et p. 215) aborda o Clown Branco (speaker, branco ou Louis) como sendo essencialmente um Escada do palhaço Augusto.

A presença do Mestre de Pista como partner

O Mestre de Pista ou de cerimônias tem

Luciane Campos Olendzki - A dupla cômica de palhaços: parceria de jogo, operação de funções e princípios da arte clownesca. Revista Arte da Cena, Goiânia, v. 2, n. 3, p. 33-52, Jul.-Dez./2016.

Disponível em: http://www.revistas.ufg.br/index.php/artce 


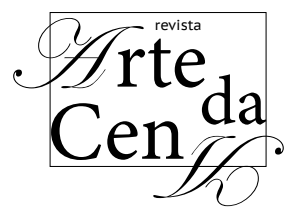

dos palhaços Augustos, também era comum nos circos europeus. O palhaço augusto Chocolat (do circo moderno europeu) comenta que na maioria das vezes os apresentadores e Mestres de Pista não apresentavam sentido de humor e imaginação para o jogo de cena, mostrando que "clowning is not their business" (TOWSEN, 1976, p. 215). Em função disso, muitos palhaços preferiram associar-se a outros palhaços para formarem duplas e outras conjunções. Widicomb (John Esdaile, 1788-1854) foi um importante Mestre de Pista, que atuava com o palhaço acrobata e cômico equestre John Ducrow, apresentando habilidade para o jogo cômico, sendo uma espécie de soberano e polo de oposição que valorizava a comicidade do palhaço - o que apresentava um delineamento inicial do que veio consolidar-se na dupla clássica Branco e Augusto (Cf. BOLOGNESI, 2003, p. 69).

\section{FUNÇÕES E RECONFIGURAÇÕES DAS DUPLAS CÔMICAS: EXEMPLARES NA PALHAÇARIA CONTEMPORÂNEA}

É importante colocar que, além da dupla de palhaços, também há junções de trios que apresentam diversas variações e adaptações de funções e papéis, tais como: dois palhaços Augustos e um Mestre de Pista ou parceiro Escada ou Crom; dois palhaços (um Augusto, outro Branco) e um palhaço Escada; três palhaços que revezam as funções de contraponto e escada, sem que cada um se fixe na tipificação de Branco ou Augusto. Nos trios é comum que um dos palhaços se destaque como protagonista ou palhaço principal (aquele que mais faz rir), geralmente, o Augusto.

No decorrer do tempo, a dupla clássica Clo$w n$ Branco e Augusto, surgida no circo moderno europeu, foi tomando outras configurações, sentidos e formas, transformando-se de modo dinâmico e criativo, perpassando diversas concepções, poéticas e estéticas da arte do palhaço. Atualmente não é usual encontrar duplas cômicas de palhaços que atuam tendo como modelo e forma os tipos clássicos Clown Branco e Augusto do circo moderno europeu. No cinema, por exemplo, a dupla Oliver Hardy e Stan Laurel (Gordo e Magro) se apresenta como um arranjo bastante singular e próprio da dupla cômica e das funções de Branco (Gordo) e Augusto (Magro).

No campo teatral da palhaçaria é possível observarmos múltiplos rearranjos, adaptações, distanciamentos, rupturas e transformações em torno dos formatos e das funções dos palhaços Branco e Augusto. Aliás, há inúmeras duplas de palhaços que sequer utilizam-se dos preceitos, funções, papéis e definições dos tipos Augusto e Branco. O papel e a figura do palhaço Branco se tornaram quase inexistentes na palhaçaria contemporânea, havendo uma proeminência e abundância de palhaços Augustos, que passam a atuar

Luciane Campos Olendzki - A dupla cômica de palhaços: parceria de jogo, operação de funções e princípios da arte clownesca. Revista Arte da Cena, Goiânia, v. 2, n. 3, p. 33-52, Jul.-Dez./2016. 


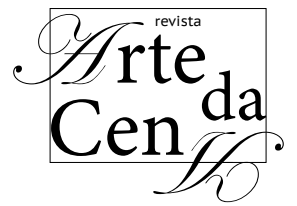

juntos em duplas, trios e outros agrupamentos.

Na cena brasileira da palhaçaria contemporânea, raros palhaços atuam no registro do palhaço Branco, como aquele que manda, se sente poderoso e superior ao Augusto. Esses palhaços geralmente atuam sem o uso de referências diretas aos formatos e configurações das duplas clássicas de Clown Branco e Augusto do circo moderno europeu. No Brasil, destacam-se as palhaças mulheres que atuam como "Brancas": Margarida (Adelvane Neia / Campinas-SP), Mafalda-Mafalda (Andreia Macera-SP) e Elizabete The Queen (Bete Dorgam-SP).

No trio de palhaços do grupo Família Burg (Campinas-SP), o palhaço Sepúlveda (Hugo Cacilhas), desempenha a função de Branco, ainda que tenha a presença e a expressividade evidentes de um tolo, atua como um tipo patético, metido à superior, inteligente, refinado e bem-letrado em contraponto ao palhaço Gonçalvez (Ivens Cacilhas), que atua como típico palhaço Augusto e vagabundo. No trio, a palhaça Bolha (Joana Piza) alterna as funções de escada, contraponto, protagonista e Augusta.

A dupla de palhaças da Dupla Cia (Campinas-SP) retoma a dupla clássica "Branco e Augusto", com suas funções e estereótipos bem definidos, no espetáculo “Atenção, respeitável público"! (2012), em que atuam a augusta Begônia (Fernanda Jannuzzelli) e a branca Madame Poatrine (Aline Olmos). A dupla pauta-se na concepção e estética do palhaço de picadeiro ou circense do circo brasileiro. O espetáculo fundamenta-se em um repertório tradicional de entradas clownescas, mormente realizado por palhaços homens, ou seja, um repertório e uma tradição tipicamente masculinos, que ganham uma nova roupagem e frescor através da atuação e jogo da dupla feminina. $\mathrm{O}$ espetáculo destaca-se pela apropriação e repetição deste repertório, em que as palhaças não se eximem das piadas picantes e tiradas com sentido sexual (características comuns das entradas dos palhaços homens, especialmente no circo e no circo-teatro brasileiros). As palhaças desempenham um ritmo contagiante de apresentação das entradas, com uso de diálogo e jogos com a participação direta do público, utilizando-se de vários procedimentos concernentes à poética $\mathrm{e}$ estética do palhaço de picadeiro.

No espetáculo “A Julieta e o Romeu” (1999) do Grupo Barracão Teatro (Campinas/SP), o palhaço Zabobrim (Esio Magalhães) e a palhaça Mafalda-Mafalda (Andreia Macera) jogam respectivamente as funções de Augusto e Branca. O espetáculo se embasa principalmente na relação conflituosa e de profunda parceria da dupla, com suas disparidades e complementaridades. A montagem da famosa obra shakespeariana "Romeu

Luciane Campos Olendzki - A dupla cômica de palhaços: parceria de jogo, operação de funções e princípios da arte clownesca. Revista Arte da Cena, Goiânia, v. 2, n. 3, p. 33-52, Jul.-Dez./2016. 
e Julieta" é o argumento do espetáculo, com o devido destaque para o protagonismo de Mafalda como Julieta. Através das tentativas desastrosas da dupla em cumprir seu objetivo principal (a montagem da peça "A Julieta e o Romeu"), o espetáculo se desenrola por sucessões de problemas, conflitos e desacordos entre os palhaços, desvios e sobreposições de situações, atrapalhação e desenvolvimento de lógica própria de cada um na realização das ações. $\mathrm{O}$ argumento, o mote e a linha narrativa do espetáculo não se perdem, tendo em vista o objetivo principal dos palhaços, ainda que a consecução deste propositalmente falhe. A falha é um dos principais princípios dramatúrgicos da poética do palhaço - o erro, a perda e a falha cômicos.

Mafalda caracteriza-se e atua como uma palhaça-diva, grande estrela, transbordando vaidade, sensualidade e superioridade em todas as instâncias (inclusive intelectual) em relação ao seu parceiro de cena, o augusto Zabobrim. Ela assume o papel, investe na função e comicidade, de uma palhaça Branca. Em sua estirpe de palhaça Branca, Mafalda exerce seu poder de superioridade e subestimação inclusive em relação ao próprio público, proferindo às pessoas pequenos insultos, provocações e rebaixamentos, em um plano lúdico. O público se deleita com as provocações e os abusos cômicos da palhaça, assim, ela diverte-se e diverte. Mafalda manda e desmanda em
Zabobrim, repreende, deprecia, impõe, xinga e agride fisicamente o seu parceiro de cena - o que se torna hilário, pois trata-se de um jogo cômico evidente ao público e um ingrediente fundamental da relação e caracterização da dupla. O público acaba por ter ainda mais empatia pelo augusto Zabobrim quando este apanha, sem deixar de gostar e rir das pancadas que Mafalda nele disfere. As gags $^{3}$ e claques ${ }^{4}$ de pancadaria, bofetadas, lutas e perseguições entre palhaços fazem parte do repertório tradicional de entradas clownescas, especialmente dos palhaços circenses que ainda mesclam acrobacias virtuosas às lutas e golpes.

Os palhaços da dupla Mafalda e Zabobrim apresentam estilos e formas de jogo e atuação diversos, porém, com afinação e escuta de conjunto para o jogo e a cena, uma parceria afinada com excelente desempenho de improvisação. A atuação de Zabobrim se fundamenta na comicidade física, com mestria e fluência de expressividade corporal, jogo cômico afiado, tempo-ritmo preciso, relação cativante e genuína com o público. Mafalda atua com maior proeminência de uso da fala.

No espetáculo solo "Utopia” (2009), Leo Bassi ${ }^{5}$ retoma a figura clássica do Clown Branco do circo moderno europeu e faz dele uma releitura, como aquele que aporta uma necessária utopia ao mundo contemporâneo, conclama necessárias utopias diante de apatias: "el Payaso

Luciane Campos Olendzki - A dupla cômica de palhaços: parceria de jogo, operação de funções e princípios da arte clownesca. Revista Arte da Cena, Goiânia, v. 2, n. 3, p. 33-52, Jul.-Dez./2016. 
de La Cara Branca, con su sabiduría antigua, su intemporalidad y su magia, es el encargado de abrir la puerta de la utopía. Un ser que posee una gran autoridad natural pero que rechaza el poder y las riquezas porque es un revolucionario genuino y pide la Luna". Neste espetáculo, Bassi usa a imagem clássica do palhaço Branco do circo moderno europeu, porém dá a ele um sentido e uma simbologia próprios, conforme suas próprias intenções, proposições artísticas e políticas. Bassi desenvolve um discurso retórico, de exposição de um ideário, com provocação e humor, apoiado na imagem clássica do palhaço Branco (isto é, veste-se como tal), investida de um conceito próprio que serve aos seus fins. No entanto, Bassi não apresenta ou desenvolve qualquer atuação e jogo como palhaço Branco. Ele usa a imagem desta figura clássica, dá-lhe um sentido próprio e desenvolve um discurso de provocação e conclamação, apoiado em estratégias de impacto e efeitos cênicos espetaculares.

Os palhaços também atuam com partners que não são e nem atuam como palhaços. Os partners realizam o papel e a função de Escada e contraponto - o que é bastante comum nas entradas clownescas do circo brasileiro, como vimos, por exemplo, no caso de atuação com o Mestre de Pista ou apresentador. No espetáculo "Amor Te Espero" (2010), o palhaço Zabobrim (Esio Magalhães) atua com um parceiro não-palhaço (Kuarahy Fillipe), que faz o papel tanto de escada ou apoio, quanto de Branco como contraponto para cenas e tiradas cômicas do augusto Zabobrim. Já pela apresentação visual é possível discernir a diferença entre os integrantes da dupla, pois apenas Zabobrim caracteriza-se como palhaço, com uso de maquiagem própria e nariz vermelho.

No espetáculo, os dois são irmãos gêmeos, o que exacerba o próprio contraste e non-sense cômicos, visto que, são tipos físicos completamente diferentes e com características diversas. Um deles é um tipo galã (o partner) - forte, bonito, grande, corajoso e lógico; e o outro (o palhaço) é um tipo desajeitado - pequeno, fraco, feio, medroso e impulsivo. Através dessas diferenças acaba se configurando um arranjo particular em que o partner ora realiza o papel de Branco, ora de escada para o palhaço augusto Zabobrim. O espetáculo apresenta uma série de contrastes para a produção da comicidade: disparidade física e non-sense entre os irmãos gêmeos; jogo complementar e diferencial entre o palhaço augusto e o partner não-palhaço (que atua ora como Escada, ora como Branco); contraste temático (morte $\mathrm{x}$ vida) - os irmãos são vendedores de um elixir prodigioso para a extrema saúde e vitalidade, porém sofrem o acosso da morte durante todo o espetáculo.

No espetáculo “Cravo, Lírio e Rosa” (1996), do Grupo Lume, também há a presença de funda-

Luciane Campos Olendzki - A dupla cômica de palhaços: parceria de jogo, operação de funções e princípios da arte clownesca. Revista Arte da Cena, Goiânia, v. 2, n. 3, p. 33-52, Jul.-Dez./2016. 
mentos da dupla Branco e Augusto na composição e jogo da dupla de palhaços Carolino e Teotônio, configurada a partir das características peculiares e próprias de cada palhaço. O palhaço Carolino (Carlos Simioni) apresenta uma soberba contida, uma assertividade precisa em sua expressividade, atitude e gestual. Ele constantemente expressa sua nobreza com desaprovação e perplexidade diante das ações e problemas relacionados ao palhaço Teotônio (Ricardo Puccetti). Carolino atua no registro do Branco e Teotônio no do Augusto. "Cravo, Lírio e Rosa” é um espetáculo lírico e singelo, em que a dupla de palhaços apresenta laços de profunda amizade e aceitação um pelo outro.

O primeiro espetáculo clownesco do grupo Lume foi "Valef Ormoso" (1992), com a atuação do trio de palhaços: Carolino, Teotônio e Cafa (palhaço de Luís Otávio Burnier ${ }^{7}$ ). Nesse trio, Carolino também ocupava o papel e a função de Branco, o palhaço Cafa como "contre-pitre"8 e Teotônio como Augusto. Também podemos analisar a atuação de Cafa como Augusto principal e o de Teotônio como segundo Augusto, ainda mais tolo, idiota e inocente. O palhaço Teotônio (Ricardo Puccetti) também atua no espetáculo solo "La Scarpetta- spetacollo artistico" (1997), dirigido pelo palhaço italiano Nani Colombaioni (19201999). Puccetti tornou-se um dos expoentes da arte da palhaçaria e da formação de palhaços no Brasil.
$\mathrm{Na}$ concepção e linha de trabalho do “palhaço pessoal", em que o palhaço não é um estereótipo, uma caricatura, um tipo fixo ou um personagem a ser representado, atuar como Branco ou Augusto não se trata simplesmente de executar funções ou papéis que fazem parte da tradição clownesca. Nessa linha, jogar ou estar mais identificado como palhaço Branco ou Augusto implica ser correspondente a qualidades e tendências associadas e intrínsecas à pessoa do ator na constituição de seu palhaço, a partir da exploração de facetas ridículas de si mesmo. Tais qualidades e tendências pessoais se manifestam e se tornam presentes por meio de processos de aprendizagem e de composição do palhaço, especialmente pelo desenvolvimento de sua prática e repertório próprios, podendo ser elaboradas conforme interesses e escolhas poéticas e artísticas de cada palhaço. As características e disposições pessoais são destacadas e tratadas como "materiais poéticos" a serem transpostos e trabalhados poeticamente para a composição do palhaço e de seu repertório (gestual, ações, reações, jogos, cenas, gags, entradas). Nessa linha, segundo Burnier (2001, p. 209): “o clown é a exposição do ridículo e das fraquezas de cada um. Logo, ele é um tipo pessoal e único (...) Não se trata de um personagem, ou seja, uma entidade externa a nós, mas da ampliação e dilatação dos aspectos ingênuos, puros e humanos (...), portanto 'estúpidos', do nosso próprio ser".

Luciane Campos Olendzki - A dupla cômica de palhaços: parceria de jogo, operação de funções e princípios da arte clownesca. Revista Arte da Cena, Goiânia, v. 2, n. 3, p. 33-52, Jul.-Dez./2016. 
Nesse sentido, atuar como Branco ou Augusto também equivale a ser um Branco ou um Augusto. A partir do entendimento e da clareza sobre qual é a tendência própria e pessoal de jogo e atuação como palhaço, se Branco ou Augusto, então, o ator investe cada vez mais nas qualidades e funções respectivas do tipo (caso tenha interesse artístico nessa concepção e modo de atuar como palhaço). Soma-se ao trabalho poético sobre determinadas qualidades e disposições pessoais, o conhecimento e o uso dos legados, tradições e referências de outros palhaços. Assim, desenvolve-se um processo criativo, dinâmico, contínuo e experimental da composição e da existência do palhaço e de seu repertório.

É importante salientar que um palhaço pode expressar e atuar múltiplas facetas, qualidades, atitudes, reações, estados e comportamentos humanos, podendo ora apresentar-se mais como Branco, ora como Augusto - conforme cada circunstância, situação e relação em que está envolvido e em jogo. A multifacetação do palhaço, através da exploração do jogo e da atuação no fluxo de todas as possíveis reações, emoções e estados, permite que este não se fixe ou se limite à estereótipos dados, podendo expressar livremente e transitar pelas várias cores e nuances da extensa paleta de possibilidades do humano e do cômico. Assim, um palhaço Augusto pode não ser apenas um palerma, idiota, subjugado e tonto que apanha e obedece, pois ele também pode mandar, agredir, ter a pretensão e o desfrute da vaidade, da superioridade, da negação e da inteligência. Qualquer fixidez dos tipos pode levar à estereotipia, à mecanicidade, à representação formal, esvaziada e decalcada.

\section{DAS DUPLAS CÔMICAS AOS PRINCÍPIOS E PROCEDIMENTOS POÉTICOS DA ARTE DO PALHAÇO}

Enfim, após a apresentação de alguns exemplares e reconfigurações em torno da dupla Branco e Augusto na cena contemporânea, pretendemos apresentar breves considerações sobre a possibilidade de análise e concepção desta dupla como portadora de princípios e procedimentos afins à própria poética clownesca.

Ao tratarmos de "princípios" nos referimos à preceitos, linhas básicas e estruturais da poética do palhaço, possíveis de serem utilizados criativamente em diversas concepções, poéticas e estéticas da palhaçaria. Princípios que podem ser operacionalizados junto à vários planos e elementos da composição clownesca, tais como, encenação, atuação, ritmo, tempo, roteiro, dramaturgia do palhaço, figurino, sonoplastia, concepção estética, etc.

Desta feita, por ora extraímos e apontamos

Luciane Campos Olendzki - A dupla cômica de palhaços: parceria de jogo, operação de funções e princípios da arte clownesca. Revista Arte da Cena, Goiânia, v. 2, n. 3, p. 33-52, Jul.-Dez./2016.

Disponível em: http://www.revistas.ufg.br/index.php/artce 
alguns possíveis princípios pertinentes à poética do palhaço que podem ser associados à dupla cômica Branco e Augusto (ou outras possíveis configurações), tais como: a) jogo, tensão e complementaridade entre contrastes e oposições; b) criação de conflito, problema, obstáculo e divergência - em um plano cômico e lúdico; c) hierarquia de relações e elementos, ainda que variável e dinâmica; d) consecução de harmonia e desarmonia ou definição de um trilho para progressão das ações e acontecimentos com constante desvio, retomada e/ou mudança de direção; e) exposição do fracasso, do erro, da falha ou do desajuste em contraponto aos padrões e formas dadas de reconhecimento e valoração; f) manipulação, subversão ou transgressão do convencionado pela burla, fantasia, brincadeira e riso.

Os papéis e funções do Branco e do Augusto aportam a possibilidade de construção de relações baseadas em contrastes e hierarquias para a produção de dissonâncias, conflitos e rupturas propícios ao cômico. Algumas das características e princípios dessas funções podem ser parte de procedimentos de composição que não se detêm apenas à configuração ou caracterização da dupla cômica, pois a dissonância, o conflito, a ruptura, $o$ contraste, o contraponto e as hierarquias podem ser elementos e dispositivos da dramaturgia do palhaço, no desenrolar das ações, situações e forma de encenação. No que diz respeito às funções de contraponto e de apoio que um palhaço pode desempenhar em relação a outro, há a possibilidade de alternância de funções, sem que um necessariamente assuma-se ou fixe-se como sendo palhaço Branco ou Augusto.

Enfim, um palhaço pode jogar e atuar transitando pelas qualidades de Branco ou Augusto, sendo mais identificado com um ou outro tipo. Assim como, pode atuar independente de tais definições, seguindo uma concepção própria acerca do palhaço - o que indubitavelmente estará relacionado aos legados dinâmicos da tradição, implicado nas manifestações e tendências de sua época. Do mesmo modo, uma dupla de palhaços pode não se atrelar à identificação de ser ou atuar como palhaço Branco ou Augusto, sem se fixar em esquemas binários de caracterização, podendo inverter, fundir e revezar qualidades, características e funções, através de jogos de contraste, contraponto e apoio, em variação poética.

O público (grande parceiro de jogo dos palhaços) também pode vir a ocupar um papel associado ao do palhaço Branco ou do Augusto, seja de forma indireta ou direta. No desenrolar da cena e da relação do palhaço com o público, este pode naturalmente sentir-se superior, mais apto, capacitado e inteligente do que o palhaço (o que é muito notável em públicos infantis, que manifestam ordens e avisos ao palhaço em cena). Nesse

Luciane Campos Olendzki - A dupla cômica de palhaços: parceria de jogo, operação de funções e princípios da arte clownesca. Revista Arte da Cena, Goiânia, v. 2, n. 3, p. 33-52, Jul.-Dez./2016. 


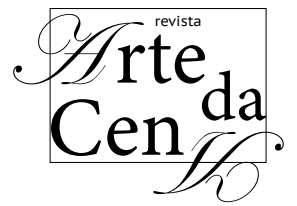

caso, de forma indireta e espontânea, o público estaria em uma qualidade de postura e de visão associadas ao do palhaço Branco em relação ao Augusto. Por outro lado, o público pode se sentir idiota e crédulo, quando o palhaço o engana, trapaceia e surpreende. O público surpreso descobre de forma prazerosa que foi enganado, como parte do jogo, tendo sido pego ou feito de bobo. Nesse caso, dá-se um movimento de inversão em que o público é desestabilizado e deslocado, trapaceado ou vencido, pela sagacidade ou esperteza do palhaço - que, até então, não passava de um estúpido excêntrico. Dessa forma, o público experimenta uma condição que pode ser associada ao do Augusto, ocupando temporariamente o papel do crédulo, inocente, trapaceado, boa-fé, manipulado sem o saber.

Quando alguém do público é convocado para uma participação direta na cena com o palhaço, esta pessoa também pode vir a exercer uma função parcial de Augusto ou Branco, conforme a proposição e a condução do palhaço em cena. Geralmente, nessas situações, o público é posto em uma condição mais aproximada do Augusto, em que recebe instruções sobre como proceder ou o que fazer, estando em um momento embaraçoso ou desconfortável, se tornando motivo de riso dos outros. Em relação à participação do público na cena ou à interação direta deste com o palhaço, é importante ressaltar, que a produção da comicidade é responsabilidade do palhaço. Afinal, esse é o ofício do palhaço, no domínio de sua mestria, técnica, forma de condução, relação, improvisação e jogo com o público - uma responsabilidade tanto poética, quanto ética. Tentar fazer graça expondo o público a um riso de deboche, depreciação ou constrangimento, parece denotar a fuga da própria responsabilidade e mestria de fazer graça, é simplesmente repassar o nariz para quem está ali para se divertir com o palhaço e sua arte, e não para ser feito de palhaço.

No uso e jogo do palhaço com objetos, também podemos conjecturar possíveis associações com as funções "Branco e Augusto", enquanto princípios e procedimentos de jogo e composição clownescos, para além da existência da dupla em cena. Por exemplo, um objeto pode cumprir o papel de Augusto em determinada ação, gag ou cena, ao quebrar, não obedecer aos comandos, responder ou operar de forma diferente, inesperada, não-convencional, não funcionar ou falhar. Esse tipo de jogo com objetos acentua as qualidades do palhaço e evidencia a maneira peculiar dele em lidar com o mundo e as coisas. Podemos citar, como exemplo, a cena clássica de Joe Jackson $\mathrm{Jr}^{9}$ em sua tentativa desastrada de andar de bicicleta, um objeto trucado e todo desmontável, com a ocorrência de uma progressão de problemas cada vez maiores, que evidenciam a estupidez, a inocência, a lógica e a racionalidade limitadas do

Luciane Campos Olendzki - A dupla cômica de palhaços: parceria de jogo, operação de funções e princípios da arte clownesca. Revista Arte da Cena, Goiânia, v. 2, n. 3, p. 33-52, Jul.-Dez./2016. 
palhaço, o que produz muita graça e empatia. Ao fim, a bicicleta se desmonta e Joe surpreende com uma saída de cena demonstrando habilidade de equilíbrio sobre a bicicleta. Tal desenlace revela uma estrutura recorrente de entradas e cenas clownescas: o palhaço idiota e inapto, ao fim, surpreende fazendo algo que ninguém conseguiria fazer, isto é, uma habilidade incomum.

Como outro exemplo, temos Hilary Chaplain ${ }^{10}$ que apresenta uma interessante entrada em que pretende desempenhar um monólogo de Shakespeare, como uma atriz clássica e dramática. No entanto, seus acessórios e indumentária lhe traem, o salto do seu sapato quebra, o colar de pérolas arrebenta, o vestido rasga. Dessa maneira, a atriz clássica e imponente acaba completamente desmontada, exposta em uma situação ridícula, construída através de uma sucessão de problemas e falhas inesperados, em que tudo foge de seu controle, através de estratégias cômicas com uso de objetos (indumentária e acessórios). Ela tenta cumprir seu objetivo até o fim, após fracassar e passar claramente por insucessos sucessivos, retoma sua ação, tentando não perder o brio e a imponência dramática. Aqui também podemos perceber procedimentos recorrentes da dramaturgia clownesca - a ação principal ou mesmo o curso de qualquer ação é interrompida, desviada ou obstaculizada por sucessão de problemas, erros e acidentes, em que ao invés do sucesso, dos méritos e do bom desempenho pretendidos o que se revela é a faceta frágil, torpe, desajustada, incipiente do humano, através da poesia cômica do palhaço.

$\mathrm{Na}$ entrada de Hilary destaca-se a discrepância cômica entre o que ela pretende parecer e fazer com o que realmente é e o que acontece; entre o querer fazer bem, ter sucesso e a falha da empreitada. A proeminência do descontrole, desmonta a palhaça e seus intentos, expondo-a em uma situação cômica e patética, contrariamente ao que ela pretendia.

A exposição e o abatimento do palhaço em uma situação ridícula, e, logo, o seu constante recomeçar e tentativa de retomada de ação e intento, além da incongruência entre intenção e acontecimento, apresenta contrastes, tensões e conflitos que acabam por aportar sob o cômico uma dimensão trágica do humano. Em torno de problemas ínfimos (que podem chegar a uma verdadeira catástrofe cômica) e de situações banais, expressa-se uma espécie de luta com a própria condição limitada do humano e com o acometer desestabilizador do movimento incontrolável do mundo, que é relativizado, afirmado e tornado motivo de riso.

O palhaço é um grande compositor do caos, programador rigoroso da desordem, do incidente, do descontrole e da surpresa. Inventa as próprias

Luciane Campos Olendzki - A dupla cômica de palhaços: parceria de jogo, operação de funções e princípios da arte clownesca. Revista Arte da Cena, Goiânia, v. 2, n. 3, p. 33-52, Jul.-Dez./2016. 


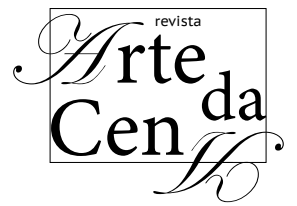

armadilhas para nelas cair, como se fosse algo inesperado, não-sabido ou previsto, para o riso e o regozijo do público. Joga com o acaso (forjado ou não), a imprevisibilidade do mundo e das coisas em movimento como se estas sobreviessem de forma inusitada, o abatessem ou carregassem para fora do eixo, do padrão e do condicionado.

$\mathrm{Na}$ exploração de relações, na dinâmica de afetar e ser afetado, na releitura interativa do mundo, o palhaço em dupla, solo ou trio pode usar diversos elementos como potenciais "parceiros de jogo", tais como, objetos, o espaço e seus componentes, um imprevisto ou determinado acontecimento do momento da apresentação que insurge ou atravessa a cena.

A arte do palhaço fundamenta-se na parceria de jogo, jogar com, se jogar e ser jogado. Seja jogar com um partner, objeto, público ou acontecimento, estando no momento presente, em vinculações e enlaces com o que lhe rodeia, sempre a querer e buscar: "vamos brincar juntos, agora"? Construir pontes para seguir passo a passo no desenvolvimento da ação, da relação, da cena e da estratégia de jogo, com presença no que acontece e no que lhe acontece. Em parceria de jogo e brincadeira com os parceiros de cena, o público, o que acontece, tornando cada apresentação um acontecimento ou jogo único.

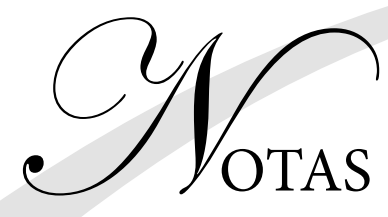

1 Lazzi: procedimento da Commedia dell'Arte, derivado de "azioni" (ação), também de "laços" curtas peças cômicas, piadas, truques, acrobacias, músicas, danças, etc., que o ator improvisador interpõe na performance, conforme sua máscaratipo, sem necessariamente fazer avançar o enredo (Cf. TOWSEN, 1976, p. 377).

2 Também conhecido como Tony de Soirée, palhaço que no circo realiza números, enquanto são feitas montagens e preparações da pista entre uma e outra atração. Deve ser um artista completo, sempre em prontidão para entrar em cena a qualquer momento, devido algum imprevisto, acidente ou desarranjo do espetáculo (Cf. GUINSBURG, 2006, p. 290).

Gags: repertório de ações, estruturadas em cenas curtas, pautadas em comicidade física, envolvendo truques, quedas, façanhas, incidentes, atrapalhações. Muito utilizadas pelos palhaços em momentos de improvisação.

Claques: cenas cômicas de pancadarias e bofetadas entre palhaços.

5 Leo Bassi, bufão e palhaço, italiano, residente em Madri/Espanha, nascido em família circense, da qual herdou extrema habilidade no malabarismo com os pés, criador de um estilo próprio e transgressor de humor.

6 Cf. http://www.leobassi.com/archives/editorial/ utopiadesde_20_de_eneroteatro_alfil_madrid.html> Acesso em: 15 de julho de 2016.

Luciane Campos Olendzki - A dupla cômica de palhaços: parceria de jogo, operação de funções e princípios da arte clownesca. Revista Arte da Cena, Goiânia, v. 2, n. 3, p. 33-52, Jul.-Dez./2016. 
7 Burnier (1956-1995), ator, palhaço, diretor, pesquisador e professor de teatro, foi fundador do grupo Lume (1985) - Núcleo Interdisciplinar de Pesquisas Teatrais da UNICAMP.

8 Contre-pitre - contra-palhaço, espécie de "Augusto do Augusto", um segundo Augusto ainda mais tolo, que não entende nada e provoca muitas trapalhadas.

$9 \quad$ Joe Jackson Jr. (1912-1991), cresceu em Nova York, típico palhaço vagabundo (tramp), herdou o número da bicicleta de seu pai, famoso palhaço austríaco, que já o realizava há 55 anos, repetindo-o nos mínimos detalhes. Cf. a entrada em: <https:// www.youtube.com/watch?v=dfTGc-Oy5I4>. Acesso em: 29 de agosto de 2016.

10 Hilary Chaplain é atriz e palhaça, americana, especialista em comédia física, membro fundadora do New York Goofs. Cf. entrada em: <https://www. youtube.com/watch? $\mathrm{v}=\mathrm{x} 90$ Tha7g2fk $>$. Acesso em: 29 de agosto de 2016.

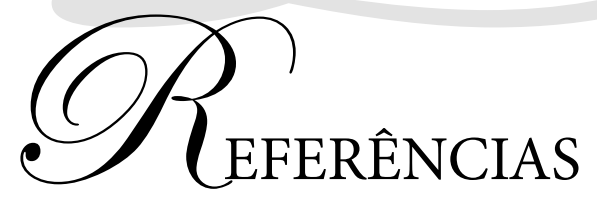

BOLOGNESI, Mário Fernando. Palhaços. São Paulo: UNESP, 2003.

BURNIER, Luis Otávio. A Arte do Ator: da técnica à representação. Campinas, São Paulo: Ed. UNICAMP, 2001.

FELLINI, Federico. Fellini por Fellini. Porto Alegre: L\&PM, 1986.

FO, Dario. Manual Mínimo do Ator. São Paulo:
SENAC São Paulo, 2004.

GUINSBURG, Jacob; FARIA, João Roberto; LIMA, Mariangela. Dicionário de Teatro Brasileiro: temas, formas e conceitos. São Paulo: Perspectiva, SESC-SP, 2006.

LECOQ, Jacques. El Cuerpo Poético: una pedagogia de la créacion teatral. Barcelona: Alba, 2003.

OLENDZKI, Luciane. Palhaçar: máscaras em uma patética-poética por rir. Programa de Pós-Graduação em Educação/ Universidade Federal do Rio Grande do Sul, 2009. Faculdade de Educação, Dissertação (Mestrado em Educação).

TOWSEN, John H. Clowns. New York: Hawthorn Books, 1976.

*UCIANECAMPOS OLENDZKIédoutoranda em Artes da Cena na Universidade Estadual de Campinas (UNICAMP), mestre em Educação e graduada em Artes Cênicas pela Universidade Federal do Rio Grande do Sul (UFRGS). É atriz, palhaça, diretora, professora de teatro. Atua na área de interpretação teatral e ensino do teatro, com ênfase na prática e na pesquisa da palhaçaria. Integrante e fundadora do grupo Firuliche e colaboradora de vários grupos teatrais, tendo como últimos espetáculos clownescos: em 2015 Pesa-me Mucho (atuação), Enfim Sós - uma tragicomédia clownesca (direção), Circo da Miséria (direção); em 2014, Do Pó ao Poporopó - Funeral Clown (direção). Atualmente pesquisa a relação da arte do palhaço e a concepção de trágico afirmativo em Nietzsche.

Luciane Campos Olendzki - A dupla cômica de palhaços: parceria de jogo, operação de funções e princípios da arte clownesca. Revista Arte da Cena, Goiânia, v. 2, n. 3, p. 33-52, Jul.-Dez./2016. 